\title{
Thyroid Stimulating Hormone Resistance
}

National Cancer Institute

\section{Source}

National Cancer Institute. Thyroid Stimulating Hormone Resistance. NCI Thesaurus.

Code C131046.

Reduced response to thyroid stimulating hormone resulting in low thyroid hormone

production despite elevated thyroid stimulating hormone, associated with mutation(s) in the TSHR gene. 